\title{
Haemolysin and Shigella Toxin Production in Multidrug Resistant Escherichia Coli Pathotypes from Clinical Specimens
}

Iliyasu MY1*, Salisu $A^{1}$, Mustapha ${ }^{2}$, Shuaibu $\mathrm{SM}^{3}$, Lawan GM${ }^{4}$, Umar AF${ }^{1}$, Agbo EB ${ }^{1}$, Uba $A^{1}$ and Deeni $Y^{5}$

${ }^{1}$ Department of Microbiology, Abubakar Tafawa Balewa University, Nigeria

${ }^{2}$ Department of Medical Laboratory Sciences, College of Health Technology, Nigeria

${ }^{3}$ Health Services Department, Abubakar Tafawa Balewa University, Nigeria

${ }^{4}$ Department of Pharmacy Technician, College of Health Technology, Nigeria

${ }^{5}$ Department of Microbiology and Biotechnology, Federal University, Nigeria

\section{Research Article}

Volume 6 Issue 1

Received Date: January 19, 2021

Published Date: March 25, 2021

DOI: $10.23880 /$ oajmb-16000188

*Corresponding author: Mahmud Yerima Iliyasu, Department of Microbiology, Abubakar Tafawa Balewa University, Bauchi, Nigeria, Tel: +2348038372210; Email: myiliyasu@atbu.edu.ng

\section{Abstract}

The acquisition and dissemination of virulent traits represent a survival advantage to bacterial pathogens. Drug resistance is on the rise among E. coli strains that cause human infections. Proper selection of antimicrobial treatment depends on the susceptibility test outcomes. A total of 178 bacterial isolates were phenotypically screened for Haemolysin and Shigatoxin production, then to obtain Multidrug Resistant (MDR) E. coli. Twelve isolates were identified and selected based on the ability to grow on Luria-Bertani (LB) agar medium containing $100 \mu \mathrm{g} / \mathrm{ml}$ Ampicillin. The isolates, coded as; U01, U02, U03, U04, U08, U10 and U11 were from urine specimens, S05, S06, S07 and S12 from stool, while B09 was from blood. The isolates were screened for multidrug resistant pattern according to Kirby-Bauer disc diffusion method. Genes hlyA and stx 1 encoding the virulence factors; Haemolysin A and Shigatoxin1 was PCR amplified and sequenced. All the isolates were resistant to Ampicillin, Cephalothin, Erythromycin, Fusidic acid, Novobiocin and Oxacillin, but sensitive to Colistin sulphate and Imipenem. Nine isolates (75\%) are sensitive to Augmentin. All the virulence genes (hlyA and stx1) are present in isolates S07 and U08. The isolates (75\%) produced 2 to 4 of each of the genes indicating a strong relationship in determining multidrug resistance. Haemolysin (hlyA) was the most common (66.7\%) gene in urine, stool and blood isolates. Most of the virulence genes sequence $(61.8 \%$ ) in this study had significant alignment (95 to $100 \%$ homology) with E.coli genome in the NCBI database. This study revealed the interplay of drug resistance and virulence at genetic levels, so advocate for further identification of the mechanisms regulating the expression of these traits, to improve the management of bacterial infections.

Keywords: Multidrug Resistance; Virulence; Haemolysin A; Shigatoxin 1; Colistin Sulphate; Imipenem

Abbreviations: MDR: Multidrug Resistant; LB: LuriaBertani; CNF: Cytotoxic Necrotizing Factor; Stx: ShigellaLike Toxins; VT1: Verotoxin; EPEC: Enteropathogenic E. Coli; ETEC: Enterotoxigenic E. Coli; EIEC: Enteroinvasive
E. Coli; DEC: Diarrhoeagenic E. Coli; Expec: Extraintestinal Pathogenic; UPEC: Uropathogenic Escherichia Coli; SMAC: Sorbitol Macconkey; LB: Luria-Bertani; ISA: Iso-Sensitest Agar; BSAC: British Society For Antimicrobial Chemotherapy. 


\section{Open Access Journal of Microbiology \& Biotechnology}

\section{Introduction}

Escherichia coli are common non-invasive commensal bacteria established as aetiological agent of various human infections. It is the most prominent cause of infectious diseases that span from the gastrointestinal tract to extraintestinal sites such as genital and urinary tract infection, septicaemia, and neonatal meningitis [1]. The E. coli that cause these diseases have specific pathogenic attributes (virulence factors) that enable them to cause disease [2]. Virulence factors are molecules and structures expressed by microbes like bacteria that enable them to achieve pathogenicity. They are very often responsible for causing disease in the host and converting non-pathogenic bacteria into dangerous pathogens [2]. In bacteria, virulence factors are often encoded on plasmids and chromosomes and can easily be spread through horizontal gene transfer [3].The virulence of the individual strains in a given infection is determined by the presence and the actual expression of the virulence genes which are found in the organisms, as well as by the environmental conditions in the host [4].

The virulent factors of E.coli play a vital role in the process of pathopoiesis. Pathogenicity of $E$. coli is due to the presence of many virulence genes that encodes some important virulence factors, such as fimbriae (fimH), invasive plasmid adhesin (ipaH),intimin (eaeA), cytotoxic necrotizing factor (CNF), haemolysin (hlyA), bundle forming pili (bfpA), heat-labile toxin (elt), heat-stable toxin (est), Shigellalike toxins (stx) and verotoxin (VT1) [5]. Several virulence genes have been used to detect human diarrhoeagenic $E$. coli. For example, eaeA, est and elt, and ipa $H$ are typically found in enteropathogenic E. coli (EPEC), Enterotoxigenic $E$. coli (ETEC), and enteroinvasive E. coli (EIEC), respectively, and have been used as genetic markers to detect their corresponding pathotypes [6,7]. Diarrhoeagenic E. coli (DEC) cause infection by a variety of complex mechanism, which include adherence toxins, elaboration of toxigenic mediators, and invasion of intestinal mucosa and transportation of bacterial proteins into the host cells [8]. Adherence to solid surfaces is a common characteristic of many extraintestinal pathogenic (ExPEC) bacteria [9]. By attaching to host structures, microbial pathogens avoid being swept along by the normal flow of body fluids (blood, urine, intestinal contents) and eliminated [9]. Uropathogenic Escherichia coli (UPEC) are the most common bacteria causing UTIs [10]. They possess specialized virulence factors, enabling them to colonize and invade to the host, disrupt the host defence mechanisms, injure host tissues, and/or stimulate a noxious host inflammatory response [11]. Virulence factors of recognized importance in the pathogenesis of UTI include diverse adhesins, toxins, siderophores, and polysaccharide capsules [10].
Bacterial virulence is responsible for rapid dissemination of these pathogens, which results in avoidable therapeutic failures in patients on antibiotics [11] and outbreaks of multidrug resistant pathogens that required expensive drugs. The treatment of $E$. coli infections is increasingly becoming difficult because of the multidrug resistance exhibited by the virulent strains [6]. Identification of intestinal E. coli strains requires that these organisms be differentiated from non-pathogenic members of the normal flora. Serogrouping of 0 antigen is not sensitive-enough to identify a strain as diarrhoeagenic, as it does not mostly correlate with the presence of virulence factors [9]. Thus, identification of diarrhoeagenic E. coli strains needs to detect genes that determine the virulence of these organisms. With the advent of PCR and gene sequencing analysis, it has become possible to detect ESBLs and virulence genes in bacterial isolates, allowing the rapid diagnosis of infections caused by pathogenic E. coli.

Previous studies describing the clinical significance of virulent $E$. coli infections have focused mainly on phenotypic characterization of isolates from cases of UTIs [11]. Measuring a phenotype in vitro does not always correlate with in vivo expression and may underestimate the presence of a virulence factor in a particular strain [10]. Phenotypic methods cannot differentiate between the specific genes responsible for pathogenicity. Molecular studies of pathogenic bacteria hold significant promise in understanding the virulence factors thereby identifying coordinates highly relevant in the development of treatment strategies. The aim of this study is therefore, to determine the genotypic characteristics of virulent $E$. coli pathotypes isolated from clinical specimens.

\section{Materials and Methods}

\section{Bacterial Isolates}

A total of 178 Escherichia coli isolates were screened on $5 \%$ sheep blood agar for haemolysin production and inoculated onto Sorbitol MacConkey (SMAC) agar media for phenotypic identification of suspected Shigatoxin producing E. coli (STEC) colonies [12]. The isolates were also selected based on the ability to grow on Luria-Bertani (LB) agar medium containing $100 \mu \mathrm{g} / \mathrm{ml}$ Ampicillin. Twelve isolates phenotypically confirmed for these virulence factors (Haemolysin and Shigatoxin) were used for genotypic characterization.

\section{Screening of Isolates for Multidrug Resistance Characteristics}

The isolates were screened for antimicrobial 


\section{Open Access Journal of Microbiology \& Biotechnology}

susceptibility pattern, multidrug resistant characteristics on Iso-sensitest agar (ISA) media (Oxoid, UK) according to Kirby-Bauer disc diffusion methods as described by Mahon C, et al. [13]. The following commercial discs were used:Combined discs M13/M14 rings (Mast Diagnostics, UK): Chloramphenicol ( $5 \mu \mathrm{g})$, Erythromycin $(5 \mu \mathrm{g})$, and Fusidic acid $(10 \mu \mathrm{g})$, Oxacillin $(5 \mu \mathrm{g})$, Novobiocin $(5 \mathrm{ug} \mu \mathrm{g})$, Streptomycin $(10 \mu \mathrm{g})$, Tetracycline $(25 \mu \mathrm{g})$, and M14 rings: Amoxycillin (30 $\mu \mathrm{g})$, Cephalothin $(5 \mu \mathrm{g})$, Colistin sulphate $(25 \mu \mathrm{g})$, Gentamycin $(10 \mu \mathrm{g})$, Sulphatriad $(200 \mu \mathrm{g})$, and Cotrimoxazole $(25 \mu \mathrm{g})$. Single discs (Oxoid): Amoxycillin-Clavulanate/Augmentin $(30 \mu \mathrm{g})$, Cefuroxime $(30 \mu \mathrm{g})$, Ceftriaxone $(30 \mu \mathrm{g})$, Cefotaxime $(30 \mu \mathrm{g})$, Ciprofloxacin $(10 \mu \mathrm{g})$ and Imipenem $(10 \mu \mathrm{g})$. The diameter zone of inhibition was measured in millimetre and results were interpreted according to British society for antimicrobial chemotherapy (BSAC) guidelines [14]. Escherichia coli ATCC 35401 were used as positive control; while E. coli K-12 DH5 $\alpha$ as negative control.

\section{Detection of Virulence Genes}

\section{DNA Extraction}

The clinical isolates were grown for 24 hours on LuriaBertani (LB) agar plates (containing $100 \mu \mathrm{g} / \mathrm{ml}$ ampicillin). Chromosomal DNA was isolated from overnight bacterial culture by boiling method as described by British Society for Antimicrobial Chemotherapy [15]. A loopful of cells from a single colony was transferred to $100 \mu$ l of sterile/double distilled water and the mixture was boiled for $10 \mathrm{~min}$, at $95^{\circ} \mathrm{C}$ in water bath to lyse the cells. The cell lysate were then centrifuged briefly (10s at $10,000 \mathrm{rpm})$. The supernatant was carefully pipetted into fresh tube and kept at $-20^{\circ} \mathrm{C}$ for further use. A $5 \mu \mathrm{l}$ of the sample was used for the PCR reaction [16]. Plasmid DNA was isolated from the samples using Qiagen miniprep protocol by alkaline lysis method according to manufacturers' instructions.

\section{PCR Amplification of Virulence Genes}

Virulence genes were amplified using hlyA and Stx1 specific primers (Integrated DNA Technologies, USA). PCR was performed in a final reaction volume of $25 \mu \mathrm{l}$, which comprises of $5.5 \mu \mathrm{l}$ sterile distilled water, $1 \mu \mathrm{l}$ (each) reverse and forward primers, $12.5 \mu \mathrm{l}$ of Master mix, Taq DNA polymerase, and $5 \mu \mathrm{l}$ of bacterial lysate (supernatant with template DNA). Amplifications were performed with the G-Storm thermocycler GS0001 (ThermoFisher Scientific, UK). PCR amplification start with initial denaturation at $94^{\circ} \mathrm{C}$ for 5 minutes, then 35 cycles of denaturation at $94^{\circ} \mathrm{C}$ for 30 seconds, annealing at $54^{\circ} \mathrm{C}$ for 30 seconds, extension at $72^{\circ} \mathrm{C}$ for 1 minute. A final extension at $72^{\circ} \mathrm{C}$ for 10 minutes was conducted, as described by Li, et al. [7]. A molecular marker $1 \mathrm{~kb}$ DNA Hyperladder (Bioline, UK) was used to assess the PCR product size (Table 1).

\begin{tabular}{|c|c|c|c|c|}
\hline Gene & Primer & oligonucleotide sequence (5' $\mathbf{-} \mathbf{3}^{\prime} \mathbf{)}$ & \multirow{2}{*}{ Size (bp) } & Reference \\
\hline \multirow{2}{*}{ HlyA } & HlyA - F & AACAAGGATAAGCACTGTTCTGGCT & \multirow{2}{*}{1177} & Jalali, et al. [17] \\
\cline { 2 - 5 } & HlyA - R & ACCATATAAGCGGTCATTCCCGTCA & \multirow{2}{*}{348} & Rono, et al. [18] \\
\hline \multirow{2}{*}{ Stx1 } & Stx1-F & CAGTTAATGTGGTGGCGAAGG & & \\
\cline { 2 - 6 } & Stx1-R & CACCAGACAATGTAACCGCTG &
\end{tabular}

Table 1: Characteristics of primer for amplification of virulence genes in the bacterial isolates.

The product was separated by gel electrophoresis on 1.0 $\%$ agarose, stained with gel red and the image was captured digitally with UV transillumination (Syngene).The product size was estimated using $1 \mathrm{~kb}$ DNA Ladder (Bioline, UK). The PCR products was purified and stored at $4^{\circ} \mathrm{C}$, before sequencing. The characteristics of the primers used and the expected amplicon size are given as shown above.

\section{Sequencing Analysis for Virulence Genes Identification}

The purified DNA from the PCR products was finally analyzed by sequencing techniques for the genes identification at the Medical Research Institute, University of Dundee (Scotland), UK.

\section{Statistical Analysis}

The data of the study was analyzed by using the SPSS version 21.1. Chi-square test was used to compare the difference in virulence genotypes in relation to MDR profile. Probability level $(P<0.05)$ was considered statistically significant.

\section{Results and Discussion}

\section{Multidrug Resistant Characteristics of the Isolates}

Multidrug resistance in bacteria is most commonly associated with the presence of plasmids which contain one or more resistance genes, each encoding a single 


\section{Open Access Journal of Microbiology \& Biotechnology}

antibiotic resistance phenotype. It has been shown that antibiotics therapy can select for antibiotic resistant strains in the enterobacterial flora and plasmid-mediated antibiotic resistance can spread in a population subjected to heavy antibiotic therapy [19]. In the present study, (Table 2) all the twelve isolates (100\%) are resistant to Amoxycillin, Cephalothin, Erythromycin, Fusidic acid, Novobiocin and Oxacillin. Eleven isolates (91.7\%) are resistant to Chloramphenicol, Cotrimoxazole, Streptomycin and Tetracycline. Eight isolates (66.7\%) are resistant to Ciprofloxacin. Seven isolates $(58.3 \%)$ are resistant to Cefotaxime, Ceftriaxone Cefuroxime and Gentamycin. Nine (9) isolates (75\%) are sensitive and three (3) isolates (25\%) are resistant to Augmentin. However, the isolates were sensitive to Colistin sulphate (100\%), Imipenem (100\%), and Augmentin (75.0\%).The E.coli isolates U03, U04, S05, S06, S07, B09, U10, U11 and S12 were sensitive to Augmentin and at least five of the isolates are also sensitive to Cefotaxime, Ceftriaxone, Cefuroxime and Gentamycin. The result showed higher resistance of the isolates to beta-lactams like ampicillin which alarms us that such drugs should no longer be used as first line of treatments in this area, as it used to be in the previous decades. These results of ampicillin-resistant E.coli are congruent to the report of Farshad, et al. [20], who found $100 \%$ resistance of their E.coli isolates to ampicillin.

\begin{tabular}{|c|c|c|}
\hline \multirow{2}{*}{ Antibiotics ( $\boldsymbol{\mu g})$} & Number of isolates (n=12) and Susceptibility pattern (\%) \\
\cline { 2 - 3 } & No. (\%)Sensitive & No. (\%) Resistant \\
\hline Amoxycillin (30) & $00(0.0)$ & $12(100)$ \\
\hline Augmentin (30) & $03(25.0)$ & $10(75.0)$ \\
\hline Ceftriaxone (30) & $05(41.7)$ & $07(58.3)$ \\
\hline Cefuroxime (30) & $05(41.7)$ & $07(58.3)$ \\
\hline Cefotaxime (30) & $05(41.7)$ & $07(58.3)$ \\
\hline Cephalothin (5) & $00(0.0)$ & $12(100)$ \\
\hline Ciprofloxacin (5) & $04(33.3)$ & $08(66.7)$ \\
\hline Cotrimoxazole (25) & $01(8.33)$ & $11(91.7)$ \\
\hline Colistin sulphate (25) & $12(100)$ & $00(0.0)$ \\
\hline Erythromycin (25) & $00(0.0)$ & $12(100)$ \\
\hline Fusidic acid (5) & $00(0.0)$ & $12(100)$ \\
\hline Gentamycin (10) & $05(41.7)$ & $07(58.3)$ \\
\hline Imipenem (10) & $12(100)$ & $00(0.0)$ \\
\hline Novobiocin (5) & $00(0.0)$ & $12(100)$ \\
\hline Oxacillin (5) & $00(0.0)$ & $12(100)$ \\
\hline Tetracycline (30) & $01(8.33)$ & $11(91.7)$ \\
\hline
\end{tabular}

Table 2: Distribution of bacterial isolates according to Antibiotic susceptibility pattern.

N.B: Zones of inhibition was interpreted according to BSAC, guidelines (2013)

The greater prevalence of resistance to common antibiotics was reported by Mohajeri, et al. [10] where maximum number of isolates $(100 \%)$ was resistant to ampicillin, carbenicillin and ceftazidime and the lowest to chloramphenicol (37\%). A maximum resistance among $E$. coli species isolates was observed against cefpodoxime $100 \%$ by Sahu, et al. [21]. The presence of multidrug resistance in this study may be related to the dissemination of antibiotic resistance among hospital isolates. Zhao, et al. [22] observed that Escherichia coli are one of the main bacterial pathogens responsible for nosocomial infections especially in immunocompromised patients. A high sensitivity of $E$. coli strains to Imipenem has been previously reported by Farshad, et al. [20]. It seems this antibiotic can serve as a medication of choice for the treatment of UTI caused by E. coli. However, it should be noted that unlimited use of a chemotherapeutic agents can gradually lead to rising antibiotic resistance.

\section{Genotypic Characteristics of Virulence Factors}

The ability of some bacteria like $E$. coli to cause diseases is determined by harbouring and acquisition of some pathogenic attributes [23]. For example, presence of cytotoxins and haemolysins in these organisms is responsible 


\section{Open Access Journal of Microbiology \& Biotechnology}

for established UTI in some women and diarrhoeal cases of medical importance [2]. In the present study (Figures 1 \& 2), all the virulence genes, hlyA and stx1 produced were found in isolates S07 and U08. This is followed by U01, U02, S06 and B09 which produced 3 of the genes, while U10 and S12 are the least with only one gene each. The results of this study show that virulence genes are more commonly found among gastroiontestinal bacteria (stool isolates) than in other cases such as UTI.

Figure1: Haemolysin A gene PCR products (chromosomal DNA) agarose gel image. Lane 01, 02, 03, 04, 05, 06, 07 and 08, are isolates that harbours hlyA gene with expected amplicon size of $1177 \mathrm{bp}$ [17]. Lane M is molecular marker (1kb DNA ladder, Bioline, UK).

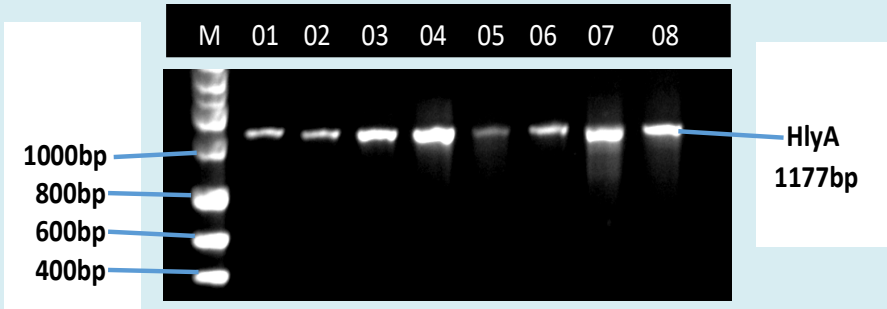

Figure 2: Shiga toxin 1 gene PCR products (chromosomal DNA) agarose gel image. Lane 02, 04, 06, 07, 08 and 09, are isolates that harbours stx11 gene with expected amplicon size of $348 \mathrm{bp}$ [18]. Lane M is molecular marker (1kb DNA ladder, Bioline, UK). Lane C is a control strain, ATCC 3450 (Virulent E. coli).

The above figure shows that the isolates, U01, U03, S05, S06, S07, U08, B09, U10, U11 and S12, harbours stx1 gene.

N.B: Zones of inhibition was interpreted according to BSAC, guidelines (2013) Birosova, et al. [23] reported that alpha-haemolytic $E$. coli strains are probably found more frequently in the intestinal tract than urinary tract. But in previous studies Tarchouna, et al. [24] reported frequent occurrence of fimH and haemolysin in patientwith UTI. Haemolysin and adherence through fimbriae are important properties of the uropathogenic E.coli. The degree of severity depends on the virulence of the responsible strains and on the susceptibility of the host [25]. A better cognition of the virulence characteristics of the microorganisms causing infection will permit the clinicians to anticipate the evolution of infection in the host. Many virulence determinants contribute to the pathogenicity of Escherichia coli.

The results indicated that the urine isolates with this high prevalence of virulence factors can be a major causative agent for UTIs in humans in the study area. In spite of the previous studies, our results showed that the urine isolates have a different virulence profile. These differences in prevalence of virulence genes showed that the properties is closely depending on geographic region and even weather conditions of each regions. It seems that the epidemiology and prevalence of virulence factors of urine isolates from patients with UTI is different in this area. It was also confirmed that haemolysin is important in pathogenesis and the pathogenicity of these gene encoding isolates. It also depends greatly on the ability of the gene to switch between conformations and this is dependent on the different alleles that can be expressed by this gene [26-28]. Another important secreted virulence factor of uropathogenic $E$. coli also found in our isolates is a lipoprotein, $\alpha$-haemolysin (HlyA), which is associated with upper UTIs such as pyelonephritis. Haemolysin production is associated with pathogenicity of E.coli, especially in the more severe forms of infection [22] (Table 3). 


\section{Open Access Journal of Microbiology \& Biotechnology}

\begin{tabular}{|c|c|c|c|c|}
\hline \multirow{2}{*}{ Virulence genes } & \multicolumn{4}{|c|}{ Specimens (n=12)/Source of Isolates } \\
\cline { 2 - 5 } & Blood (n= 01) & Stool (n=04) & Urine (n=07) & Total(\%) positive \\
\hline HlyA & 01 & 02 & 05 & $08(66.7)$ \\
\hline Stx 1 & 01 & 02 & 03 & $06(50.0)$ \\
\hline
\end{tabular}

Table 3: Genotypes of Virulence factors according to type of specimen.

At high concentrations, HlyA is able to lyse erythrocytes and nucleated host cells, a process that may enable extraintestinal pathogens like UPEC to better cross mucosal barriers, damage effect or immune cells, and gain enhanced access to host nutrients and iron stores [29]. Haemolysin is known to confer selective advantage to the pathogen by releasing iron from lysed erythrocytes and enhances pathogenicity by destroying phagocytic cells and epithelial cells. Haemolysin production has also been shown previously to influence pathogenicity. Haemolysins has been proposed to inflict direct cytotoxic effects on renal epithelium $[22,26]$.

The hlyA gene prevalence $(66.7 \%)$ in our studies is significantly associated $(\mathrm{p}<0.05)$ with both UTI and gastrointestinal disorders, as the gene was detected in both urine and stool isolates. There was a clear relation between tissue damage and the presence of haemolysin in this study. Prevalence of these genes differs on the basis of phylogenetics, geographical distribution, and clinical presentation. A huge variation in the frequencies of these genes was recorded worldwide [24]. Haemolytic activity in $E$. coli has been attributed to many types of Haemolysin genes. A new class of haemolysin represents a novel bacterial gene designated $h l y F$ gene that is strongly associated with $E$. coli isolates from bloodstream infection [30].

Virulence is due to a plasmid such as HlyA that encodes genes required for invasion, cell survival and apoptosis of macrophages [10]. The virulence genes in E. coli are often located on transmissible genetic elements that can be transferred to E. coli recipient strains. These virulence determinants give each pathotype the capacity to cause a clinical syndrome with distinctive epidemiologic and pathologic characteristics [27] and are therefore ideal targets for the determination of the pathogenic potential of any given E. coli variant. Shiga toxin (stx) is one of the major virulence factors involved in E. coli 0157:H7 pathogenesis based on immune reactivity, toxins are classified as either Stx1 or Stx2, which damage intestinal epithelial cells and kidneys, causing haemorrhagic colitis and haemolytic uremic syndrome, respectively [9]. The stx gene in E. coli 0157:H7 is associated with a prophage, and different subtypes of shigatoxin are identified [24].

The prevalence of stx genes in our studies was low. However, these virulence genes are usually associated with occurrence of diseases. A study in Egypt by Morsi and Elsaid Tash [31], showed similar distribution of virulence genes. This indicates that some social and environmental factors may contribute in the virulence pattern of $E$. coli in different communities. The negative isolates for some of the genes in our study may be part of the normal flora that lack these virulent genes or may be due to the possibility of corresponding gene mutations, as negative test results does not always indicate the absence of the corresponding operon while a positive result usually confirms the presence of the virulence genes. When antibiotic resistance was tested among the virulent isolates, a significant relation was observed $(\mathrm{P}<0.06)$, where most of the isolates harbouring the virulence genes were multidrug resistant.

Shigella toxin-producing E. coli (STEC) were identified as the cause of diseases in human host due to its association with E. coli 0157:H7 involved in diarrhoea, purpura and the haemolytic uremic syndrome. Many water and foodborne disease episodes have been reported from different geographical areas worldwide [30-33]. Whatever, STEC is associated with a wide range of human diseases such as bloody diarrhoea, haemorrhagic colitis (HC), and haemolyticuremic syndrome (HUS). The Shiga toxins either 1 (stx1) or 2 (stx2) interfere the binding of aminoacyl tRNA to the ribosomes and preventing the protein synthesis resulting in depurinating specific residues of the host cell ribosomes after internalization. The biological activities of stx 1 and $s t x 2$, involving cytotoxicity to Vero and HeLa cells, are similar, but the immunological properties are different [33].

\section{Virulence Gene Sequences with Significant Alignment}

Escherichia coli are a common and widespread bacterium associated with various infectious diseases of both intestinal and extraintestinal sites. This is due to acquisition and dissemination virulence genes that determined their pathogenicity. The worldwide burden of these diseases is staggering, with hundreds of millions of people affected annually. Eight E. coli pathovars have been well characterized, and each uses a large arsenal of virulence factors to subvert host cellular functions to potentiate its virulence [33,34]. Haemolysin A (hlyA) gene from isolates $\mathrm{S} 12$ shows a high significant sequence alignment at $97 \%$ homology with the EPEC strain, E. coli 0128:H27 chromosomal DNA, complete 
genome (CP024243.1). Enteropathogenic Escherichia coli (EPEC) strains were the first E. coli strains recognized as important pathogens in diarrhoeal diseases [6]. Even today, EPEC strains are the major bacterial cause of neonatal and infantile gastroenteritis throughout the world, especially in developing countries [33]. Enteropathogenic Escherichia coli (EPEC) implicated in gastrointestinal infections represents a major causative agent of infant diarrhoea [35]. It has been recognized to exhibit a great pathogen-attributable risk of death in infants eleven months of age and younger [36]. Studies have shown that its morbidity and mortality rates, especially in developing countries, are quite significant [37].
It is conceivable that virulence genetic determinants, if located on the same genetic platform as antimicrobial resistance genes, may be co-mobilized under antimicrobial selective pressure [38]. In this study, isolates S07 and U08 which carry all the virulence genes are resistant to 17 (85\%) out of the 20 antibiotics tested, while U01 and S06, which harboured 3 of the virulence genes are resistant to 18 (90\%), with U02 (85\%) and B09 (65\%). The remaining isolates which mainly carry hlyA genes are resistant to 10 to 17 antibiotics. The control of $E$. coli infections is therefore becoming complicated due to the increasing resistance to antibiotics (Table 4).

\begin{tabular}{|c|c|c|c|c|c|}
\hline DNA Sample & Identified strain & Gene & Type of genome & Sequence ID & \% ID \\
\hline HlyA 03 & E. coli EC11 & cDNA & complete genome & CP027255.1 & 97 \\
\hline HlyA 05 & E. coli 0128:H27 & cDNA & complete genome & CP024243.1 & 97 \\
\hline HlyA 06 & Ent. hormaechei 34983 & cDNA & complete genome & CP010377.1 & 94 \\
\hline HlyA 08 & K. pneumoniae KpvK54 & cDNA & complete genome & CP023134.2 & 84 \\
\hline HlyA 09 & E. coli strain MEM & cDNA & complete genome & CP012378.1 & 93 \\
\hline HlyA 10 & E. coli 0104:H4 & cDNA & complete genome & CP027394.1 & 97 \\
\hline HlyA 11 & E. coli RM14721 & cDNA & complete genome & CP027105.1 & 98 \\
\hline HlyA 12 & E. coli HS13-1 & cDNA & complete genome & CP026491.1 & 91 \\
\hline Stx1 06 & Ent. cloacae AR-0093 & cDNA & complete genome & CP027604.1 & 95 \\
\hline Stx1 07 & P. aeruginosa AR-357 & cDNA & complete genome & CP027166.1 & 93 \\
\hline Stx1 08 & K. pneum.WCHKP649 & cDNA & complete genome & CP026585.2 & 100 \\
\hline Stx1 09 & E. coli RM14721 & cDNA & complete genome & CP027105.1 & 100 \\
\hline Stx1 12 & E. coli WCHEC05237 & cDNA & complete genome & CP026580.1 & 100 \\
\hline
\end{tabular}

Table 4: Virulence genes sequence producing significant alignment.

\section{Conclusion}

This study observed that the virulence genes hlyA and stx are harboured in the isolates,indicating a strong relationship in determining MDR of E.coli pathotypes. Therefore increased alertness of clinicians and enhanced testing of virulence factors by laboratories are necessary to reduce chemotherapeutic failure. The present study has shown the capacity of $E$. coli to adapt and survive in different tissues through virulence and developing drug resistance. The expression of virulence factor(s) may depend on the pathogens and varies in different kinds of infections. Most of the isolates in this study are resistant to commonly used antibiotics, but continued prescription of Augmentin is still advocated.

\section{References}

1. Gally DL, Stevens MP (2017) Microbe Profile: Escherichia coli 0157:H7- Notorious relative of the Microbiologist's workhorse. Microbiology 163(1): 1-3.

2. Merino I, Porter SB, Johnston BD, Clabots C, Shaw E, et al. (2017) Virulence genes and sub-clone status as markers of experimental virulence in a murine sepsis model among Escherichia coli sequence type 131 clinical isolates from Spain. PLoS One 12(11): e0188838.

3. Baker KR, Sigurdardottir HH, Jana B, Guardabassi L (2017) Cephem potentiation by inactivation of nonessential genes involved in cell wall biogenesis of $\beta$-lactamase-producing Escherichia coli. Antimicrob Agents and Chemother 61(3): e01773.

4. Shruthi N, Ravish K, kumar R (2012) Phenotypic Study of Virulence Factors in Escherichia coli Isolated From Antenatal Cases, Catheterized Patients, and Faecal Flora. J Clin Diagn Res 6(10): 1699-1703.

5. Muniea M, Hammer JA, Hertwig S, Appel B, Brussow H (2012) Shiga Toxin-Producing Escherichia coli 0104:H4: 


\section{Open Access Journal of Microbiology \& Biotechnology}

a New Challenge for Microbiology. Appl Environ Microbiol 78(12): 4065-4073.

6. Unno T, Han D, Jang J, Widmer K, Gwangpyo K, et al. (2011) Genotypic and Phenotypic Trends in Antibiotic Resistant Pathogenic Escherichia coli Isolated from Humans and Farm Animals in South Korea. Microbes Environ 26(3): 198-204.

7. Li S, Qu Y, Hu D, Shi Y (2012) Comparison of extended spectrum beta-lactamases producing Escherichia coli with non-ESBLs producing E.coli: drug-resistance and virulence. World J Emerg Med 3(3): 208-212.

8. Nataro JP, Kaper JB (1998) Diarrhoeagenic Escherichia coli. Clin Microbiol Rev 11(1): 142-201.

9. Ochoa JT, Ruiz J, Molina M, Martha DV, Gil AI, et al. (2009) High frequency of Antimicrobial drug resistance of diarrheagenic Escherichia coli in infants in Peru. Am J Trop Med Hyg 81(2): 296-301.

10. Mohajeri P, Khademi H, Ebrahimi R, Farahani A, Rezaei M (2014) Frequency distribution of virulence factors in uropathogenic Escherichia coli isolated from Kermanshah in 2011-2012. Int J Appl Basic Med Res 4(2): 111-116.

11. Sharma S, Bhat GK, Shenoy S (2007) Virulence factors and drug resistance in Escherichia coli isolated from extraintestinal infections. Indian J Med Microbiol 25(4): 369-373.

12. Cheesbrough M (2006) District Laboratory Practice in Tropical Countries. Part 2, $2^{\text {nd }}$ (Edn.), Cambridge University Press, Cambridge, UK.

13. Mahon C, Manuselis G (1995) Textbook of Diagnostic Microbiology, $3^{\text {rd }}$ (Edn.), WB Saunders, Philadelphia, pp: 1134.

14. British Society for Antimicrobial Chemotherapy (BSAC) (2013) Methods for Antimicrobial Susceptibility Testing. Version 12.

15. Sambrook JF, Russell DW (2001) Molecular Cloning: A Laboratory Manual, $3^{\text {rd }}$ (Edn.), Cold Spring Harbor Laboratory Press, pp: 2100.

16. Bali EB, Açik L, Sultan N (2010) Phenotypic and molecular characterization of SHV, TEM, CTX-M and extendedspectrum Beta-lactamase produced by Escherichia coli, Acinobacter baumannii and Klebsiella isolates in a Turkish hospital. African J Microbiol Res 4(8): 650-654.

17. Jalali HR, Pourbakhsh A, Fallah F, Eslami G (2015) Genotyping of Virulence Factors of Uropathogenic
Escherichia coli by PCR. Novelty in Biomed 4: 177-181.

18. Rono SJ, Kaikai R, Esamai F, Mibei E, Odundo E (2014) Pathotypes and virulence markers in E.coli associated with diarrhoea among HIV-seropositive and negative children below five years in Western Kenya. Eur Scientific J 10(27): 180-195.

19. Christopher AF, Hora S, Ali Z (2013) Investigation of plasmid profile, antibiotic susceptibility pattern multiple antibiotic resistance index calculation of Escherichia coli isolates obtained from different human clinical specimens at tertiary care hospital in Bareilly-India. Annals of Tropical Med Pub Health 6(3): 285-289.

20. Farshad S, Ranjbar R, Japoni A, Hosseini M, Anvarinejad M, et al. (2012) Microbial susceptibility, virulence factors, and plasmid profiles of uropathogenic Escherichia coli strains isolated from children in Jahrom, Iran. Arch Iranian Med 15(5): 312-316.

21. Sahu SK, Dalal AS, Bansal G (2011) Detection of extendedspectrum $\beta$-lactamases in clinical isolates of $E$. coli and Klebsiella species from Udaipur, Rajasthan. Biomed Res 22(3): 367-373.

22. Zhao L, Chen X, Zhu X, Yang W, Dong L, et al. (2009) Prevalence of virulence factors and antimicrobial resistance of uropathogenic Escherichia coli in Jiangsu province (China). Urology 74(3): 702-707.

23. Birosova E, Siegfried M, Kmetova A, Makara A, Otro A, et al. (2004) Detection of virulence factors in alphahaemolytic Escherichia coli strains isolated from various clinical materials. Clin Microbiol Infec 10(6): 569-573.

24. Tarchouna M, Ferjani A, Selma WB, Boukadida J (2013) Distribution of Uropathogenic virulence genes in Escherichia coli isolated from patients with urinary tract infection. Int J Infec Dis 17(6): e450-e453.

25. Shruthi N, Kumar R, Ravi K (2012) Phenotypic Study of Virulence Factors in Escherichia coli Isolated From antenatal Cases, Catheterized Patients, and Faecal Flora. J Clin Diagn Res 6(10): 1699-1703.

26. Arisoy M, Aysev D, Ekim M, Ozel D, Kose SK, et al. (2006) Detection of virulence factors of Escherichia coli from children by multiplex PCR. Int J Clin Pract 60(2): 170173.

27. Tiba MR, Yano T, Da Silva DL (2008) Genotypic characterization of virulence factors in Escherichia coli strains from patients with cystitis. Rev Inst Med Trop Sau Paulo 50(5): 255-260.

28. Yun KW, Kim HY, Park HK, Kim W, Lim IS (2014) Virulence 


\section{Open Access Journal of Microbiology \& Biotechnology}

factors of uropathogenic E. coli of urinary tract infections and asymptomatic bacteriuria in children. J Microbiol Immunol Infec 47(6): 455-461.

29. Annapurna YVS, Reddy BS, Lakshmi VV (2014) Multidrug resistance and Virulence Phenotypes among Uropathogenic Escherichia coli. Int J Curr Microbiol Appl Sci 3(6): 222-229.

30. Aljanaby AAJ, Alfaham QMH (2017) Phenotypic and Molecular Characterization of some Virulence Factors in Multidrug Resistance Escherichia coli Isolated from Different Clinical Infections in Iraq. American J Biochem Molec Biol 7(2): 65-78.

31. Morsi SS, Tash RM (2016) Virulence Determinants among Extended-Spectrum B- Lactamases producers of Uropathogenic Escherichia coli isolates In Zagagig University Hospitals, Egypt. Egyptian J Med Microbiol 25(2): 101-108.

32. Cheng CH, Tsau YK, Kuo CY, Su LH, Lin TY (2010) Comparison of extended virulence genotypes for bacteria isolated from pediatric patients with urosepsis, acute pyelonephritis and acute lobar nephronia. Paediatr Infect Dis J 29(8): 736-740.

33. Croxen MA, Finlay BB (2010) Molecular mechanisms of
Escherichia coli pathogenicity. Nat Rev Microbiol 8(1): 26-38.

34. DupontA,Somer F, Zhang K, RepnikU, Basic M, etal.(2016) Age-dependent susceptibility to enteropathogenic Escherichia coli (EPEC) infection in mice. PLoS Pathol 12(5): e1005616.

35. Wook K, Hak Y, Hee YK, Park K, Kim P (2014) Virulence factors of uropathogenic Escherichia coli of urinary tract infections and asymptomatic bacteriuria in children. J Microbiol Immunol Infect 47(6): 455-461.

36. Ochoa TJ, Contreras CA (2011) Enteropathogenic E. coli (EPEC) infection in children. Curr Opin Infec Dis 24(5): 478-483.

37. Ifeanyi CIC, Ikeneche NF, Bassey BE, Morabito S, Graziani C, et al. (2017) Molecular and phenotypic typing of enteropathogenic Escherichia coli isolated in childhood acute diarrhoea in Abuja, Nigeria. J Infec Dev Ctries 11(7): 527-535.

38. Villa L, García-Ferńndez A, Fortini D, Carattoli A (2010) Replicon sequence typing of IncF plasmids carrying virulence and resistance determinants. J Antimicrob Chemother 65(12): 2518-2529. 